International Journal of

Prognostics and Health Management

A Peer Reviewed and Indexed International Journal

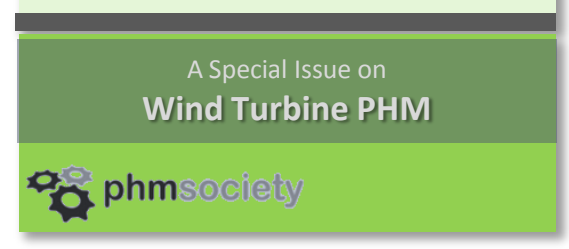

CALL FOR PAPERS

Special Issue of the

International Journal of Prognostics and Health Management

\section{Wind Turbine Prognostics and Health Management}

\author{
EDITORS-IN-CHIEF \\ David He, Ph.D., Professor, Department of Mechanical and Industrial Engineering, \\ University of Illinois at Chicago, USA \\ Eric Bechhoefer, Ph.D., Chief Engineer, NRG Systems VT, USA \\ Abhinav Saxena, Ph.D. Research Scientist, \\ NASA Ames Research Center, CA USA \\ e-mail: editor@iiphm.org
}

\section{Associate Editors}

Kai Goebel

NASA Ames Research Ctr., USA

Karl M. Reichard

Pennsylvania State Univ., USA

Irem Tumer

Oregon State Univ., USA

Editorial Board

Serdar Uckun

Palo Alto Research Ctr., USA

Sherif Abdelwahed

Mississippi State Univ., USA

Eric Bechhoefer

NRG Systems, USA

Jeff Bird

National Research Council, CA

Gautam Biswas

Vanderbilt University, USA

Leonard Bond

Pacific Northwest Natl. Lab, USA

Kuan-Jung Chung

Natl Changhua Univ. of Edu, China

Ivan Cole

CSIRO, Australia

Neil Eklund

GE Global Research, USA

Torbjörn Fransson

SAAB AB, Sweden

Len Gelman

Cranfield University, UK

Antonio Ginart Impact Technologies, USA

Felix Heimes BAE Systems, USA

Giovanni Jacazio Politecnico di Torino, Italy

Stephen Johnson

NASA Marshall Space Flt Ctr, USA

Seth Kessler

Metis Design. USA

Jay Lee

University of Cincinnati, USA

Sony Mathew

CALCE, Univ. of Maryland, USA

Vincent Rouet

EADS, France

Ginger Shao

Honeywell International Inc., USA

Peter Struss

Technical Univ. Munich, Germany

Bo Sun

Beihang University, China

Liang Tang

Impact Technologies, USA

George Vachtsevanos Georgia Institute of Tech., USA

Weizhong Yan

GE Global Research, USA

Marcos Orchard

University of Chile. Chile

Jose Celaya

NASA Ames Research Ctr., USA

Byeng D. Youn

Seoul National University, Korea
The International Journal of Prognostics and Health Management (IJPHM) is the premier online open access journal related to multidisciplinary research on Prognostics, Diagnostics, and System Health Management. This special issue is focused on advances in research in condition monitoring of wind turbines.

Wind power generating capacity was $239 \mathrm{GW}$ at the end of 2011 , with a further $46 \mathrm{GW}$ of installed capacity to be operational by the end of 2012 . While only providing $2.8 \%$ of the energy produce in the United States, its is anticipated that by 2030 , fully $20 \%$ of the electrical energy will come from wind. This widespread deployment of industrial wind projects will require a more proactive maintenance strategy in order to be more cost competitive with traditional energy systems, such as natural gas or coal. This will be particularly true for offshore wind projects, where availability of the site for maintenance can be restricted for extend period of time due to weather. Prognostics and Health Management of these assets can improve operational availability while reducing the cost of unscheduled maintenance.

\section{Topics of Interest:}

- Physics gearbox degradation and failure

- Remaining useful life estimation for gearbox

- Tower and Foundation structural health monitoring

- Blade crack detection and structural health monitoring

- Inverter/IGBT Fault detection and estimation of RUL

- Oil debris monitoring techniques

- Oil condition monitoring, effect of oil on component life

- Vibration, acoustic emissions based gear/bearing detection
- Offshore requirements for CBM/PHM

- Use of SCADA information for diagnostics/prognostics

- Integration of oil/vibration and SCADA for PHM

- Relationship between gust loads and gearbox damage

- Wind turbulence and damage accumulation on rotating parts

- Curtailment as a strategy to extend RUL

- Optimal scheduling of repair resources based on RUL

- Prognostics and its relation to balance of plant operation
This CFP solicit papers that discuss the emerging art and science of wind turbine condition monitoring. A secondary goal is to document and benchmark the state-of-the-art in wind turbine component RUL estimation.

\section{Submission Types:}

Full-Length Regular Papers: Regular papers should describe new and carefully confirmed findings. Experimental procedures and results should be given in detail sufficient for others to replicate the work.

Technical Briefs: Technical briefs describe a single result, experiment, or technique of general interest in short manuscripts enough to describe experimental procedures and clearly, and interpret the results in the context of other research.

Communications: Communications are short manuscripts that include (but are not limited to) rebuttals and/or counterexamples of previously published papers and are suitable for recording the results of complete small investigations or giving details of new models or hypotheses, innovative methods, techniques or apparatus.

Survey Papers: Survey papers are of a tutorial or review nature covering emerging research topics in PHM or describe the best current practice, detailed characteristics and performance. These papers cover areas of general interest.

Special Issue Editor: David He, UIC, davidhe@uic.edu, Eric Bechhoefer, ebechhoefer@gmail.com

Submission Instructions: Please submit your manuscripts directly by going to the society webpage and follow instructions for journal submissions. There you will find an option to select the special issue.

Invitation to Present: Accepted papers are eligible for Annual Conference of the PHM Society, October 13-17, 2013, New Orleans, LA USA

Deadline for Submission: March 1, 2013 